\title{
Use of signature whistles during separations and reunions by wild bottlenose dolphin mothers and infants
}

\author{
R.A. Smolker ${ }^{1}$, J. Mann ${ }^{2}$, B.B. Smuts ${ }^{1}$ \\ ${ }^{1}$ Department of Psychology, University of Michigan, 580 Union Drive, Ann Arbor, MI 48109, USA \\ ${ }^{2}$ Department of Psychology, Georgetown University, Washington, DC 20057, USA \\ Received: 22 July 1992/ Accepted after revision: 26 May 1993
}

\begin{abstract}
We examine the contexts and patterns of "signature" whistle production by wild bottlenose dolphin mother-infant pairs (Tursiops spp.) to gain insight into the functional significance of whistles. Results are based on focal observations and simultaneous recordings of underwater vocalizations. Whistles occur primarily when mother-infant pairs are separated, and the probability of whistles increases with distance of separation. The timing of whistles during separations varies, but whistles tend to be produced in repetitive series and are generally concentrated toward the later stages of the separation, i.e., during the process of reunion. Although we focused on infants, mothers do not appear to whistle during separations as frequently as infants. Infant whistles may function to facilitate reunions by conveying information to the mother concerning the infant's motivation to reunite and/or its location. Infant whistles could induce a cooperative response from the mother including approach, slowing to allow the infant to catch up or whistling. Highly individualized signature whistles may be particularly useful in a fission-fusion society in which individuals (mothers and infants as well as adults) join and leave temporary parties in a fluid manner, yet maintain consistent, long-term associations with particular individuals.
\end{abstract}

\section{Introduction}

Dolphins rely on acoustic signals to negotiate their physical and social environment. Yet, because of methodological limitations, behavioral and acoustic studies of dolphins are rare, particularly in the wild. Echolocation is clearly used in the pursuit of prey, but little is known about the natural contexts and functions of the majority of dolphin vocalizations. This study investigates the function of a common acoustic signal, the "signature

Correspondence to: R.A. Smolker whistle", by wild bottlenose dolphin infants and their mothers.

Many delphinid species are known to produce narrow-band, frequency-modulated whistles as part of a larger repertoire of sounds used for social communication (Herman and Tavolga 1980). Bottlenose dolphins (Tursiops spp.) produce whistles ranging from about 4 to at least $20 \mathrm{kHz}$ (Dreher 1961; Evans and Prescott 1962; Dreher and Evans 1964; Herman and Tavolga 1980) and ranging in duration from 0.1 to 3.6 seconds (Lilly and Miller 1961; Evans and Prescott 1962; Caldwell et al. 1990).

Caldwell and Caldwell (1965) recorded whistles produced by captive dolphins temporarily stranded out of water and demonstrated that each dolphin within a group produced a unique whistle, which they referred to as that individual's "signature". In this and subsequent research (Caldwell and Caldwell 1968, 1971, 1979; Caldwell et al. 1973, 1990), individual-specific stereotyped signature whistles were found to be widespread among captive delphinids, including bottlenose dolphins as well as three other species (Stenella plagiodon, Lagenorhyncus obliquidens, Delphinus delphis). In a recent review of their research, Caldwell et al. (1990) analyzed 22,250 whistles from 120 captive bottlenose dolphins and reported that on average (mean across individuals) $94 \%$ of the whistles produced by an individual were its signature. The Caldwells suggested that the individualized whistles of dolphins may serve as identifiers used to establish and maintain contact between individuals.

This hypothesis is consistent with the nature of bottlenose dolphin societies, which appear to depend upon the abilities of individuals to locate and identify particular other individuals using acoustic cues. Bottlenose dolphin communities are very large, without clearly delineated boundaries (Wells et al. 1987; Smolker et al. 1993). Everywhere that they have been studied, they exhibit a "fission-fusion" grouping pattern, that is, individuals typically associate in temporary parties, the composition of which changes frequently as individuals 
join and leave in a fluid manner, and all members of the social network are never found in a single party (Tayler and Saayman 1972; Saayman and Tayler 1973; Würsig and Würsig 1977; Würsig 1978; Wells et al. 1980, 1987; Ballance 1990; Smolker et al. 1993). Yet underlying these temporary associations are some remarkably stable, long-term associations. For example, groups of two to four adult male bottlenose dolphins in Shark Bay, Western Australia consistently associate with each other, traveling, foraging, and socializing together for many years, perhaps throughout their adult lifetimes (Smolker et al. 1993). Females also associate consistently with particular other females, although not as consistently as some males. Females associate with their dependent calves usually for about 4 years but occasionally up to 6-10 years (Wells et al. 1987, unpublished data from Shark Bay).

Given that dolphins maintain consistent associations with other individuals within a large, fluid social network, and given that distances between associates can range up to at least several kilometers at times (i.e., when scattered during foraging or when in separate parties), individual identification and localization are critical. The individualized signature whistles characteristic of these animals appear well-suited to this task.

Almost nothing is known about how whistles are used by wild dolphins. To date, most research on signature whistles has been done with temporarily restrained dolphins (e.g. Caldwell and Caldwell 1968, 1971, 1979; Caldwell et al. 1973, 1990; Sayigh et al. 1990). In these studies, the effects of extremely reduced space, limited social variation and stress could alter or limit whistle use. On the other hand, it is extremely difficult to study free-ranging dolphins. Because dolphin sound production does not involve externally moving mouthparts, it is generally not possible to identify the source of a whistle when more than one dolphin is present, except when bubbles are released during whistle production. Freeranging dolphins spend much of their time out of sight below the water surface and are difficult to track continuously, particularly in poor weather conditions.

For both practical and theoretical reasons, mothers and infants provide opportunities to examine the use of signature whistles. First, mothers and infants frequently separate and reunite, simulating the fission-fusion nature of the social system at large. Second, mother-infant pairs often travel alone, or, when separated from each other, as lone individuals. Thus it is often possible to assume confidently that any relatively loud whistles are from one or the other pair member.

J. Mann and B.B. Smuts (in prep.) found that some bottlenose dolphin infants in Shark Bay, Western Australia spend nearly $20 \%$ of their time at distances greater than $20 \mathrm{~m}$, sometimes as far as several hundred meters from their mothers (see below), despite potentially high rates of predation on infants by sharks. Numerous large shark species inhabit the area and many calves and adults bear the scars of shark bites. Estimated rates of shark predation and other causes of infant mortality, including the possibility of stranding on the shallow weed banks or encounters with toxic organisms such as scorpionfish
(Pterois volitans) or stonefish (Synanceja horrida) have not yet been determined.

We hypothesized that mothers and infants must keep in contact during separations using vocalizations, and that the ability to reunite quickly and effectively is of particular importance. Anecdotal evidence from early observations of a captive colony of bottlenose dolphins (McBride and Hebb 1948; McBride and Kritzler 1951; Tavolga 1966) and from temporary captures of wild dolphins (Sayigh et al. 1990), as well as from our own observations, suggested that mothers and infants often whistle when separated. To better understand the function of signature whistles, we examine their use in a well-defined, relatively simple natural context, motherinfant separations.

\section{Methods}

Study site. Our study site incorporates an area of approximately $130 \mathrm{~km}^{2}$ offshore of the Monkey Mia camp on the east coast of the Peron Peninsula, which bisects Shark Bay, in Western Australia. The dolphins are a relatively small, ventrally speckled form of bottlenose dolphin, formerly referred to as Tursiops aduncus, but now considered to belong to Tursiops truncatus, a species distributed worldwide that varies considerably with geographic location (Ross and Cockcroft 1990). Since research began in 1982, over 400 dolphins have been individually identified using photographic records of distinctive natural markings on their dorsal fins. Long-term data collection has focused on demography, social behavior, activity budgets and acoustic communication (Connor and Smolker 1985; Smolker and Richards 1988; Connor et al, 1992a, 1992b; Smolker et al. 1993). Several dolphins (up to eight individuals in 1988) routinely enter shallow water and accept fish fed by hand from tourists. These provisioned individuals also interact with each other while at the Monkey Mia shoreline. Approximately 70 other non-provisioned dolphins are habituated to the presence of our boats and are followed regularly at distances ranging from 5 to $30 \mathrm{~m}$. The shallow and calm waters of Shark Bay provide excellent observation conditions for studying dolphin behavior in the wild.

Mother-infant study. In 1988, JM and BBS began a long-term study of infant behavior, using focal follow sampling (Altmann 1974). Infants are followed in $3.5-\mathrm{m}$ aluminum dinghies for as long as possible during a day (ranging from $30 \mathrm{~min}$ to $9 \mathrm{~h}$; median $=3.5 \mathrm{~h}$ ). We report here primarily on $114 \mathrm{~h}$ of focal infant observations conducted with simultaneous recordings of underwater vocalizations between 21 April and 15 July 1990.

During focal follows, scan samples were used to measure mother-infant proximity (we remained with infants when they were separated from their mothers). When in deep water $(>3 \mathrm{~m})$, mother-infant proximity was assessed at the onset of surfacing bouts (a series of breaths occurring between dives). In shallow water $(<3 \mathrm{~m})$ continuous observation was possible and mother-infant proximity was assessed at 2.5 -min intervals. When mothers and infants were close $(<20 \mathrm{~m})$, we could assess distances reliably, but at larger distances $(>20 \mathrm{~m})$ this was more difficult and the shortest possible distance was recorded. Our results therefore conservatively estimate the proportion of time infants spend at large distances.

In 1990, nine mother-infant pairs were followed. All data from three infants were excluded because we were unable to obtain enough recordings of the infant's whistles. Much of our data was collected from observations of two 1.5-year-old males, Cookie and Smokey. We focused on these two infants because (1) they were very commonly encountered (reducing search time) and were particularly well habituated to being followed and (2) they both had distinctive signature whistles that were easy to identify by ear. Given the difficulty of collecting data on free-ranging dolphins, we decided to 
focus on these two individuals rather than attempting to obtain smaller samples from a larger number of individuals. For statistical tests, we treat each mother-infant separation as an independent event, in spite of the fact that repeated observations of (primarily) the same two individuals are not formally independent.

Recording. During the 1990 follows, dolphin sounds were recorded using a Sony TCD $5 \mathrm{M}$ cassette recorder and a custom-made hydrophone with a $1-\mathrm{kHz}$ high-pass filter (to reduce water noise). This system was responsive up to about $16 \mathrm{kHz}$. To reduce engine noise interference, an electric motor was used to power the boat and the hydrophone was towed alongside. Analysis of whistles was done using a Kay Elemetrics 5500 Digital Sound Processor. We listened to (during long periods of silence) and recorded dolphin vocalizations as continuously as possible during follows.

Methodological limitations. Because dolphins are often out of sight when below the water surface, keeping track of the movements of a focal individual usually depends on sighting the dolphin as it surfaces to breathe. Such surfacings are sometimes brief and hard to see under poor weather conditions and/or when the dolphins' travel direction is difficult to predict. When recording vocalizations, data collection was sometimes interrupted when noise produced by water flow across the hydrophone interfered with dolphin sounds. This typically occurred when we had to speed up in order to stay close to the dolphin. When the focal dolphin was far from the hydrophone, whistles were fainter and more easily masked. Because of these problems, we use slightly different samples for each of the analyses below, discarding cases where relevant information was lacking.

Determinining the source of whistles. Several lines of evidence were used to attribute whistles to infants or their mothers. If the mother and infant were the only dolphins in sight, we could assume that any whistles we heard were probably from one of these two individuals. Since we stayed with infants when they separated, the infant was often the only animal nearby, and all relatively loud whistles were assumed to have been from him or her. It was sometimes possible to confirm that infants were whistling when whistles were broadcast into air as the infant's head broke through the water surface to
BABY SIGNATURE WHISTLES

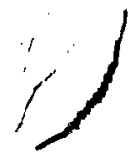

SMOKY
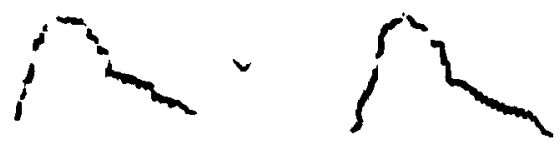

COOKIE

DRONE
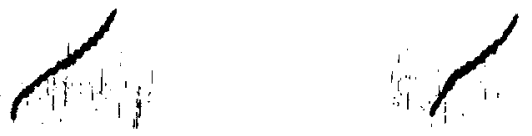

ZIPPY
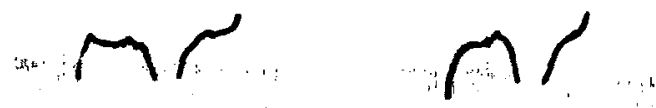

QUASI
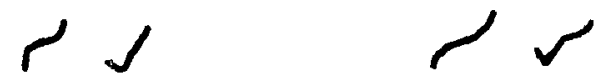

\section{WINNIE}
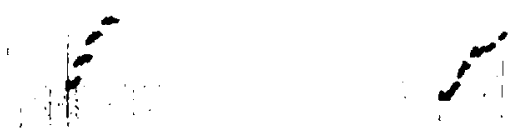

Fig. 1. Infant signature whistles. Spectrographs of the signature whistles of each of the six infants included in the analyses (two selected from different dates for each infant)

breathe. Whistle amplitude changes as dolphin orientation and/or distance relative to the hydrophone changes. Such variations could often be correlated with the infant's movements (i.e. amplitude decreasing as the infant moves away from us, or increasing as the infant orients towards us). To identify the infant's signature whistle,

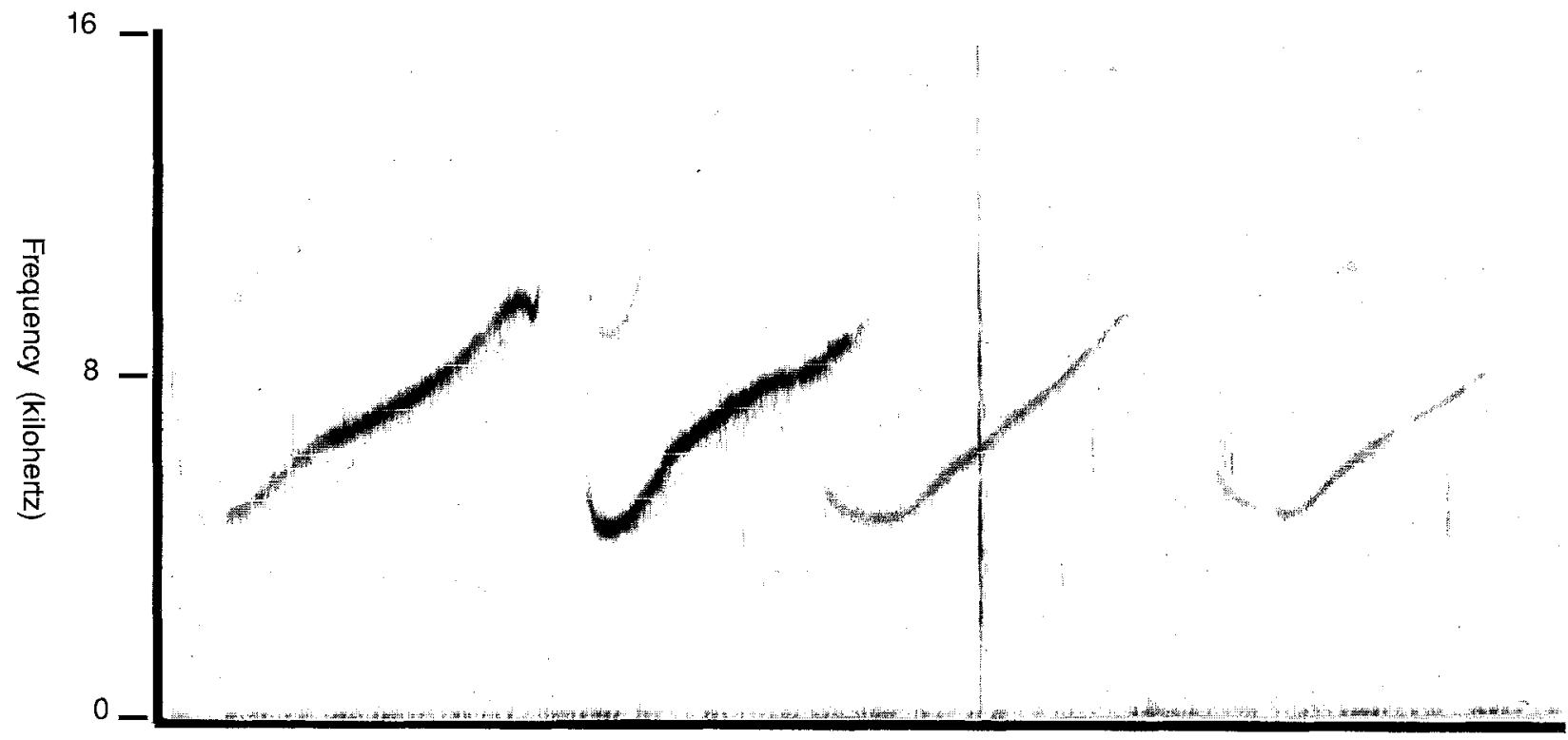

Time $250 \mathrm{~ms}=$

Fig. 2. Whistles recorded during an onshore herding session from Yogi and her older son Booboo in 1986. Overlapping renditions of a single type of whistle (indicating production of the same whistle by more than one individual) with different amplitudes (the second, fainter rendition was presumably from Booboo, who was further from the recording hydrophone) 
we used the following three criteria: (1) we identified the whistle type that predominated during recordings made in the presence of the infant; (2) we determined that this was the only whistle type occurring when the infant was alone; and (3) we determined that this whistle was not present when the infant was not present. Infant signatures are illustrated in Fig. 1.

Because dolphins may occasionally imitate the signatures of other individuals (Tyack 1986), and because infants sometimes adopt their mother's signature (Sayigh et al. 1990), the potential for confusion of whistles produced by infants with those produced by their mothers (and vice versa) is of concern. We have recorded mother-infant pairs producing the same whistle type on at least three occasions outside this study period. Indications that more than one individual was producing the same whistle included renditions of the whistle overlapping in time, irregularly spaced intervals between whistles in a series, and/or alternating amplitude differences corresponding to the different distances of mother and infant from our hydrophone (see Fig. 2).

During this study, we observed overlapping renditions of the same whistle type on just one occasion, involving the whistle typically produced by the male infant, Cookie. These nine overlapping renditions occurred during a separation at the provisioning area and were therefore excluded from the analyses. We assume that the other dolphin producing the Cookie-type whistles was his mother, Crookedfin, who was approximately $40 \mathrm{~m}$ from him. Crookedfin either has the same signature whistle as her son or imitated Cookie's signature whistle on this occasion. In spite of many opportunities between 1982 and 1990 to record whistles from Crookedfin at the provisioning area, we have not obtained identified or even suspected examples of whistles from her (she apparently did not whistle often), nor were there unidentified examples of the "Cookie-type" whistle recorded in Crookedfin's presence previous to his birth. Whistles were recorded from Yogi (mother of Smokey) on several occasions, both during this study and in previous years. She always produced the same whistle type (her signature), which was different from Smokey's (but the same as whistles recorded from her older son, Booboo, illustrated in Fig. 2). We are not familiar with the signatures of the mothers of other infants included in our analyses. Although we cannot unambiguously assign whistles to either infants or their mothers, circumstantial evidence summarized above suggests that most whistles of the type associated with a particular infant (its signature) were in fact produced by that infant.

\section{Results}

\section{Mother-infant proximity}

The proportion of time infants spent at different distances from their mothers shows surprising uniformity across the first 4 years of life. Because of high rates of infant mortality and limited sample sizes, both crosssectional and longitudinal data from 1988-1990 were combined. Several infants were sampled in consecutive years, and one infant was sampled over 3 years. Although Fig. 3 indicates that infants spent somewhat less time very near to their mothers $(<5 \mathrm{~m})$ and more time at far distances $(>20 \mathrm{~m})$ by the time they were 3-4 years old, age differences were not statistically significant. Note that the older ages are under-represented in our sample with only three infants in each of the top two age classes. Although we have not analyzed data for infants younger than 4 months, very young calves probably spend more time in close proximity to their mothers than do older calves.

Considerable individual variation occurs in motherinfant proximity. For example, several 6-month-old in-

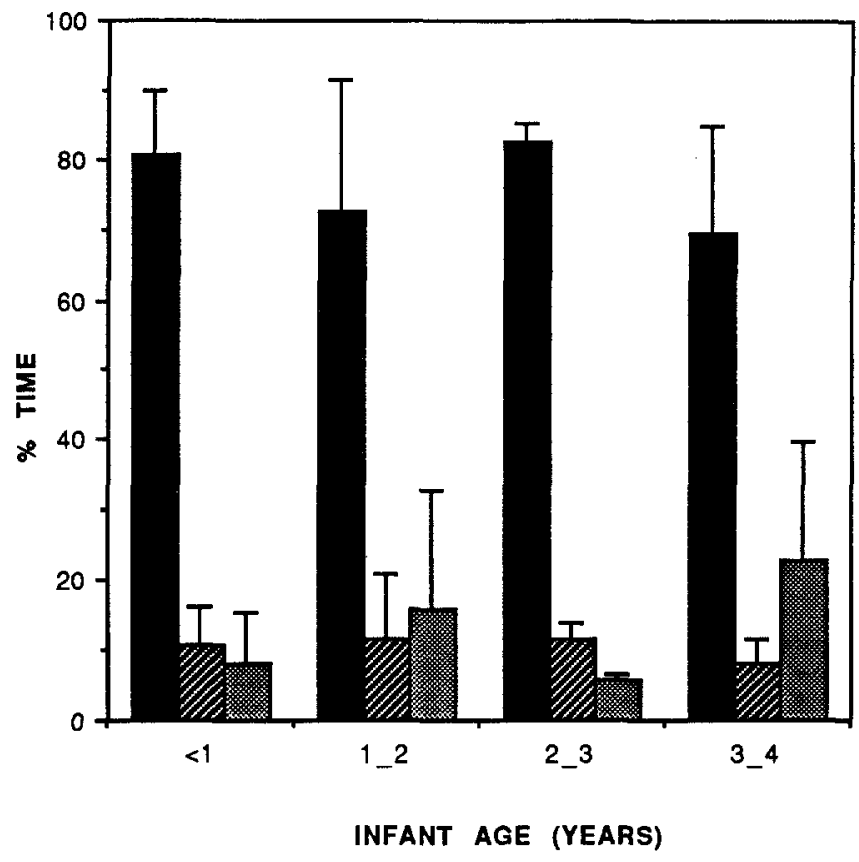

Fig. 3. The mean proportions of time mothers and infants spent at three different distance classes (together, filled columns; close, shaded columns; and far stippled columns) at different infant ages. Data consisted of 9193 scan samples of mother-infant distance collected during a total of $332.5 \mathrm{~h}$ of focal observations $(133 \mathrm{~h}$ of observation of nine infants at $<1$ year old, $108 \mathrm{~h}$ on seven infants at 1-2 years old, $50 \mathrm{~h}$ on three infants at $2-3$ years old and $41.5 \mathrm{~h}$ on three infants at 3-4 years old)

fants spent approximately $15-20 \%$ of the time more than $20 \mathrm{~m}$ away from their mothers, while others of the same age spent only $3-5 \%$ of the time more than $20 \mathrm{~m}$ away. One infant became completely independent from his mother at an age of only 3-4 years (and was therefore excluded from the 3-4 year old class in the analysis of Fig. 4).

When infants were with their mothers, they typically traveled in a position close to and just behind and below the mother's genital/mammary region, referred to as "infant position" (Connor and Smolker 1985). We recorded all observed changes in and out of infant position. Infants were considered to be "together" with their mothers when in infant position, or when traveling consistently at a very close distance $(<2 \mathrm{~m})$. We distinguished three different types of mother-infant separations. (1) "Infant position breaks" were defined as short distance separations when mother and infant broke out of infant position and moved up to $5 \mathrm{~m}$ apart before returning to infant position. (Separations to distances from 5 to $20 \mathrm{~m}$ were also considered infant position breaks when they were of less than 2 min duration, although these rarely occurred). Infant position breaks typically occurred when the mother suddenly accelerated or changed direction in pursuit of prey. (2) "Close separations" were defined as periods when mother and infant moved apart to distances between 5 and $20 \mathrm{~m}$ for 2 or more min. (3) "Far separations" were defined as periods when mother and infant moved to distances greater than $20 \mathrm{~m}$ apart. 


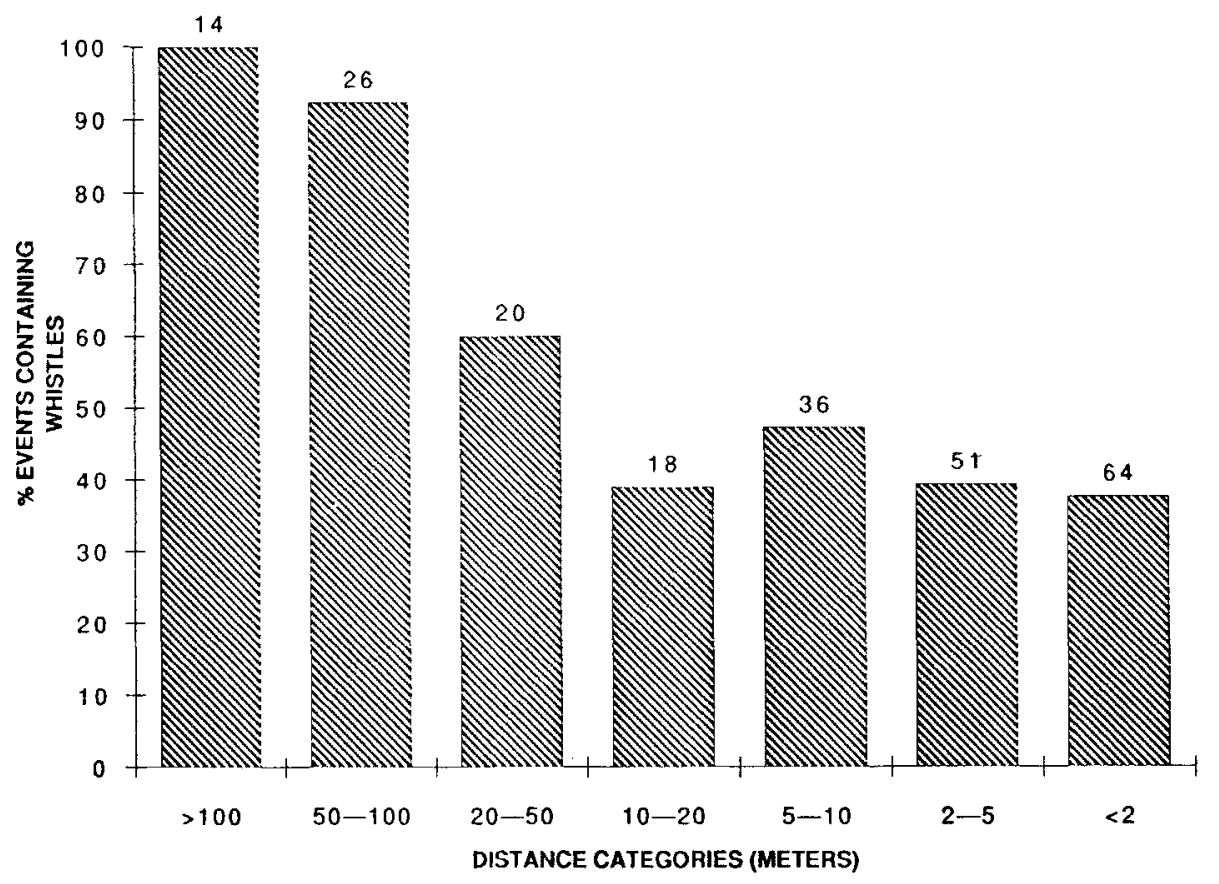

Fig. 4. The percentage of separations during which infants whistled as a function of maximum distance. Distance classes (in meters) are infant position breaks ( $<2 \mathrm{~m}, 2-5 \mathrm{~m}$ ), close separations $(5-10 \mathrm{~m}, 10-20 \mathrm{~m})$ and far separations $(20-50 \mathrm{~m}, 50-100 \mathrm{~m}$ and $>100 \mathrm{~m})$. Numbers above bars are the number of events within each class

Table 1. Summary of data, including the number of different days on which each infant was observed and the number of far and close separations and infant-position breaks recorded for each infant

\begin{tabular}{lccclcc}
\hline Infant & Cookie & Smokey & Quasi & Zippy & Drone & Winnie \\
\hline Age (years) & 1.5 & 1.5 & 1.5 & 3.5 & 1.5 & 0.5 \\
Sex & male & male & male & female & male & female $^{\mathrm{a}}$ \\
Days observed & 19 & 15 & 3 & 2 & 2 & 3 \\
Far separations & 17 & 17 & 9 & 6 & 4 & 2 \\
Close separations & 8 & 14 & 5 & 5 & 6 & 8 \\
Infant position breaks & 45 & 27 & 10 & 6 & 21 & 14 \\
\hline
\end{tabular}

All focal follows were conducted between 21 April and 15 July 1990

a Winnie was thought to be female based on incomplete views of her genital area, but this was never confirmed

In 1990, we recorded vocalizations during 109 far separations, 46 close separations and 123 infant position breaks. Of the 109 far separations, we discarded 54 from analysis because of poor monitoring conditions or because the separation involved the habituated motherinfant pair, Crookedfin and Cookie, while they were near the Monkey Mia provisioning area. The remaining 55 separations form the basis for analysis of far separations (Table 1). During some separations, short periods occurred when we were unable to monitor vocalizations, and for 6 of the 55 far separations, we found the infant already separated from its mother. Far separations ranged from $2 \mathrm{~min} 36 \mathrm{~s}$ to $47 \mathrm{~min} 29 \mathrm{~s}$ in duration ( $m e a n=15 \min 35 \mathrm{~s}, \mathrm{SD}=10 \mathrm{~min} 32 \mathrm{~s}$ ), and ranged from 20 to approximately $300 \mathrm{~m}$ in distance (28 were to distances greater than $50 \mathrm{~m}$ ).

\section{Contexts of whistling}

Whistles rarely occurred when infants were together with their mothers, but did occur during breaks in infant position and separations. For the two males, Smokey and Cookie, we tallied all occasions when their signature whistles were recorded. These were then scored as (1) with mother, (2) infant position break, or (3) separated (far and close distance separations pooled). Rather than scoring every whistle recorded during 1990, we scored "whistle events" as follows: When the infant was with its mother, a new whistle event was scored if $5 \mathrm{~min}$ had passed since the last whistle occurred. Otherwise each whistle event encompassed all whistles occuring during a given separation.

Out of a total of 82 whistle events for Cookie (excluding five cases where we could not assess the distance between Cookie and his mother), only six (7\%) occurred when he was together with his mother, while $29(35 \%)$ occurred when a break in infant position occurred, and $47(57 \%)$ occurred when he was separated from his mother. For Smokey, a total of 51 whistle events were scored (excluding four cases where we could not assess the distance between Smokey and his mother). Of these, four $(8 \%)$ occurred when he was together with his mother, seven (13\%) occurred when a break in infant position happened, $39(76 \%)$ occurred when he was separated from his mother.

Whistles usually stopped when infants reunited with their mothers (returned to infant position or $<2 \mathrm{~m}$ from 
the mother). We scored two time periods, "before" and "after" reunion, for the presence or absence of whistles. "Before" refers to the minute just prior to reunion; "after" refers to the first minute following reunion. We considered only the 30 far separations for which we were confident that we could hear any whistles that occurred both immediately before and and after reunion. In 14 of these, there were no whistles during the minute before or the minute after reunion. In 11 cases, whistles occurred before but not after reunion. In four cases whistles occurred before and after reunion. In one case whistles occurred after, but not before reunion. Pooling all separations (regardless of which infant was involved), whistles were significantly more likely to occur before than after reunion (McNemar's test, $\chi^{2}=6.75, \mathrm{df}=1, P<0.01$ ).

As maximum separation distance increased, the percentage of separations containing whistles likewise increased (Fig. 4). Of the 14 separations to distances over $100 \mathrm{~m}, 100 \%$ contained whistles, while only $38 \%$ of the 64 separations to distances less than $2 \mathrm{~m}$ contained whistles.

It is difficult to separate the effects of separation distance from duration since these are not independent variables (greater distances take longer to travel). However, we can take advantage of a subsample of (1) exceptionally long duration $(>8 \mathrm{~min}$ ) but close distance $(<20 \mathrm{~m})$ separations and (2) exceptionally short duration $(<8 \mathrm{~min})$ but far distance $(>20 \mathrm{~m})$ separations. There were 98 mother-infant separations (not including infant-position breaks) for which we could identify the duration and maximum distance of the separation and were certain whether or not whistles occurred. Of these, 13 were short duration-far distance separations and 13 were long duration-near distance separations. Each was scored for the presence or absence of whistles. We applied a multiple logistic regression test to examine the independent contributions of duration, distance, and the interaction of the two, towards predicting whistles. Distance of separation was the only factor that contributed significantly (full model estimate results, with $d f=3, P<0.001$. Distance: coefficient $=1.08, \mathrm{SE}=0.29$, ratio $=3.79$. Duration: coefficient $=0.17, \mathrm{SE}=0.29$, ratio $=-0.61$. Interaction: coefficient $=0.29, \mathrm{SE}=0.29$, ratio $=1.03$ ).

\section{Timing of whistles within far separations}

Whistles tend to be produced repetitively in series (separated by intervals of $1 \mathrm{~min}$ or less, by definition). Far separations during which infants whistled contained one to five whistle series. The number of whistles per series was highly variable, ranging from 1 to 124 whistles.

If mothers and infants use whistles to maintain acoustic contact throughout separations, we would expect whistles to be distributed fairly evenly throughout each separation. In contrast, if mothers and infants use whistles more specifically to facilitate the reunion process, we would expect whistles to begin just before they begin to reduce the distance between them.

We analyzed the timing of whistles within far separations relative to the time at which (1) mother and infant

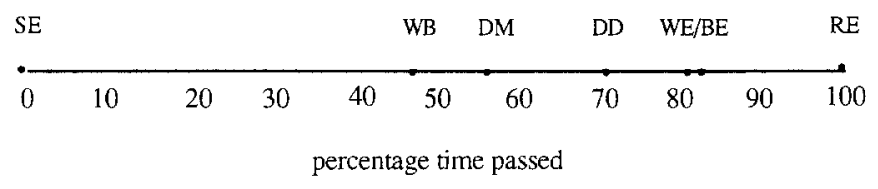

Fig. 5. Timeline for key behavioral elements of far separations (separation $=S E$, maximum distance $=D M$, whistles begin $=W B$, decrease distance $=D D$, whistles end $=W E$, beeline travel $=B E$, reunion $=R E$ ). Times are calculated as the percentage of separation time passed when the behavior occurred, averaged across all 55 far separations. The values for means and SDs are listed along with the number of separations used to calculate that mean (because it was not possible to assess the timing of all elements for all separations, each calculation is based on a slightly different sample). $\mathrm{SE}=0 \%$, $\mathrm{DM}=$ mean $=56 \%, \quad$ S.D. $=23 \%, \quad n=51, \quad \mathrm{WB}=$ mean $=49 \%$, S.D. $=28 \%, n=49, \mathrm{DD}=$ mean $=72 \%, \mathrm{~S} . \mathrm{D} .=17 \%, n=34, \mathrm{WE}=$ mean $=81 \%$, S.D. $=21 \%, n=48, \mathrm{BE}=$ mean $=83 \%$, S.D. $=13 \%$, $n=35, \mathrm{RE}=100 \%$

separated, (2) the infant was at the maximum distance from its mother, (3) the distance between mother and infant began to decrease, (4) the infant began direct, rapid travel back to its mother ending in the reunion, referred to as "beelining" (this did not occur in every separation), (5) the mother and infant reunited, (6) the first whistle during the separation occurred, and (7) the last whistle occurred.

Because separation durations varied, we converted from absolute to relative time. For each separation we calculated the percent of total separation time passed when each of the above seven elements of separations occurred. Figure 5 shows a summary separation "timeline" for the 55 far separations. The points represent an average percentage of time passed when the behavior occurred. On average, the first whistle tended to occur at $49 \%$ of the time into the separation $(\mathrm{SD}=28 \%)$, just before the maximum distance was achieved (mean $=56 \%$, $\mathrm{SD}=23 \%$ ). On average, the last whistle occurred at $81 \%$ of the time into the separation ( $\mathrm{SD}=21 \%$ ), after the average time at which distance began to decrease (mean $=72 \%, \mathrm{SD}=17 \%$ ), but just slightly before the time at which beeline travel began (mean $=83 \%, \mathrm{SD}=13 \%$ ).

Considerable variation in the sequence and timing of whistles relative to separation elements occurred, as indicated by the large standard deviation values, some of which may have been due to variations in monitoring conditions. Despite this variability, whistles tended to be concentrated toward the later stages of the separation and, on average, began before the distance between mother and infant decreased or the infant began direct beeline travel towards its mother.

\section{Mother's whistles}

Although we focused primarily on infants in this study, we were surprised by the paucity of evidence that mothers also whistle in this context (even less than we expected given our closer proximity to infants rather than to mothers). Except for a few cases described below, there were rarely indications that mothers and infants exchanged whistles of different types, nor did alternating 
amplitude or overlapping renditions suggest that whistles of the same type were exchanged. This led us to focus on the mothers of Cookie and Smokey (Crookedfin and Yogi, respectively) during eight separations. On three of these occasions, whistles occurred, but increasing amplitude corresponding to the infant's approach indicate that the whistles were produced solely by the infant. There were no cases of whistles likely to have been produced by Crookedfin (except during a separation occurring at the provisioning area and therefore not included in analyses. During this separation, overlapping renditions of the Cookie-type whistle were thought to have been produced by Cookie and Crookedfin). In one case, a single whistle occurred that was probably produced by Yogi. In a second case, seven whistles (in series) were clearly produced by Yogi. She had been foraging and consistently traveling away from Smokey, when she suddenly turned approximately $180^{\circ}$ and traveled back toward him, directly approaching our boat in the process as she whistled. She traveled approximately $150 \mathrm{~m}$ to reunite with Smokey. The whistles she produced on both occasions were the same as those recorded from her (and also from her older son, Booboo) on two consecutive days, 3 years earlier (Fig. 2).

Mothers clearly do whistle during at least some separations, and it is likely that we missed some whistles produced by mothers because they were further from us. However, in this context mothers do not seem to whistle as reliably or as repetitively as do infants.

\section{Effects of stress}

While we obtained little evidence for mothers' whistles during our offshore data collection, there were many separations recorded at the provisioning area during which mothers clearly did whistle, sometimes repetitively. Mother-infant whistle production has usually been studied during forced separations, either in captivity or during capture-release procedures with wild animals. In our study, a naturally occurring situation, "herding", provided the opportunity to examine the effects of forced separation on mother-infant whistling. Male dolphins cooperate in groups of two or three to herd females aggressively (Connor et al. 1992a, b). Herding typically begins when males locate and chase and/or "display" around a female, who thereafter remains with the males for up to at least 4 weeks in some cases. During this time, the males apparently coerce the herded female into maintaining proximity through the use of an acoustic threat, referred to as "pops" (R.C. Connor and R.S. Smolker in preparation), and through aggressive acts including hitting, biting and chasing when the females attempt to escape.

During the period 1986-1988, the three provisioned males aggressively herded females, bringing them into the shallow waters and into proximity with humans at the Monkey Mia provisioning area, where the females normally did not go. This appeared to be stressful to many of the herded females, as evidenced by their attempts to flee (despite male aggression), and other signs of agitation (e.g. circling repeatedly, rapid swimming, jerky movements). Some of the females herded into the provisioning area had infants, from whom they were sometimes separated. This allowed us to record motherinfant separations under conditions when mothers were inhibited from approaching their infants (by the males), and infants likewise may have been inhibited from approaching their mothers while they were so close to humans.

We analyzed in detail a 48-min recording session which took place in 1986 involving a mother (Yogi) and her 2-3 year old male calf (Booboo), while Yogi was herded into the provisioning area and Booboo remained at least $50 \mathrm{~m}$ offshore most of the time. During this session, 63 whistles were definitely produced by Yogi (determined by localizing the sound source when she whistled with her head partially out of the water or while very close to the observer when underwater). All of the identified whistles were of a single type and 527 whistles of this type were recorded during the session. Of these, 306 were produced so that two renditions overlapped in time (Fig. 2) and therefore must have been produced by two different individuals. We assume that all whistles of this type were produced by either Yogi or Booboo, and that overlaps occurred when both whistled together. Although we were never able to definitively identify Booboo as the source of any whistles, this assumption is supported by the fact that the whistles were produced in a pattern of alternating loud whistles known or assumed to have been produced by Yogi, who was close to the hydrophone, and faint whistles, assumed to have been produced by Booboo, who was far from the hydrophone. As Booboo approached Yogi, the amplitude difference became less and less marked, until we could no longer distinguish a difference, and stopped as the pair reunited.

A second case involved the herding of a mother with her female infant (mother-calf pair 2) at the provisioning area in 1987. The infant separated from her mother, remaining 30-60 $\mathrm{m}$ from her on two occasions during the 50 -min recording session. A total of 28 whistles of one type (Fig. 6 bottom) were identified as having been produced by the mother (7), the infant (16) or one of the two (5). A total of 402 whistles of that type were recorded, and 35 overlaps occurred, indicating that both mother and infant were whistling.

A third case involved the herding of another mother with her female infant (mother-calf pair 1) at the provisioning area in 1988. During a 41-min recording session, 93 whistles of one type (Fig. 6 top) were identified as having been produced by the mother. A total of 152 whistles of that type occurred, with no overlapping renditions. No whistles could be definitively assigned to her infant, but it was noted at times during the session that the infant was whistling, and the whistles occurring at those times were different from those produced by the mother. In this case, it is likely that most of the whistles were produced by the mother.

The frequent, and in some cases, incessant whistling of the mothers during the above separations differed from separations recorded offshore. We heard whistling by both mothers (close to our hydrophone) and infants 

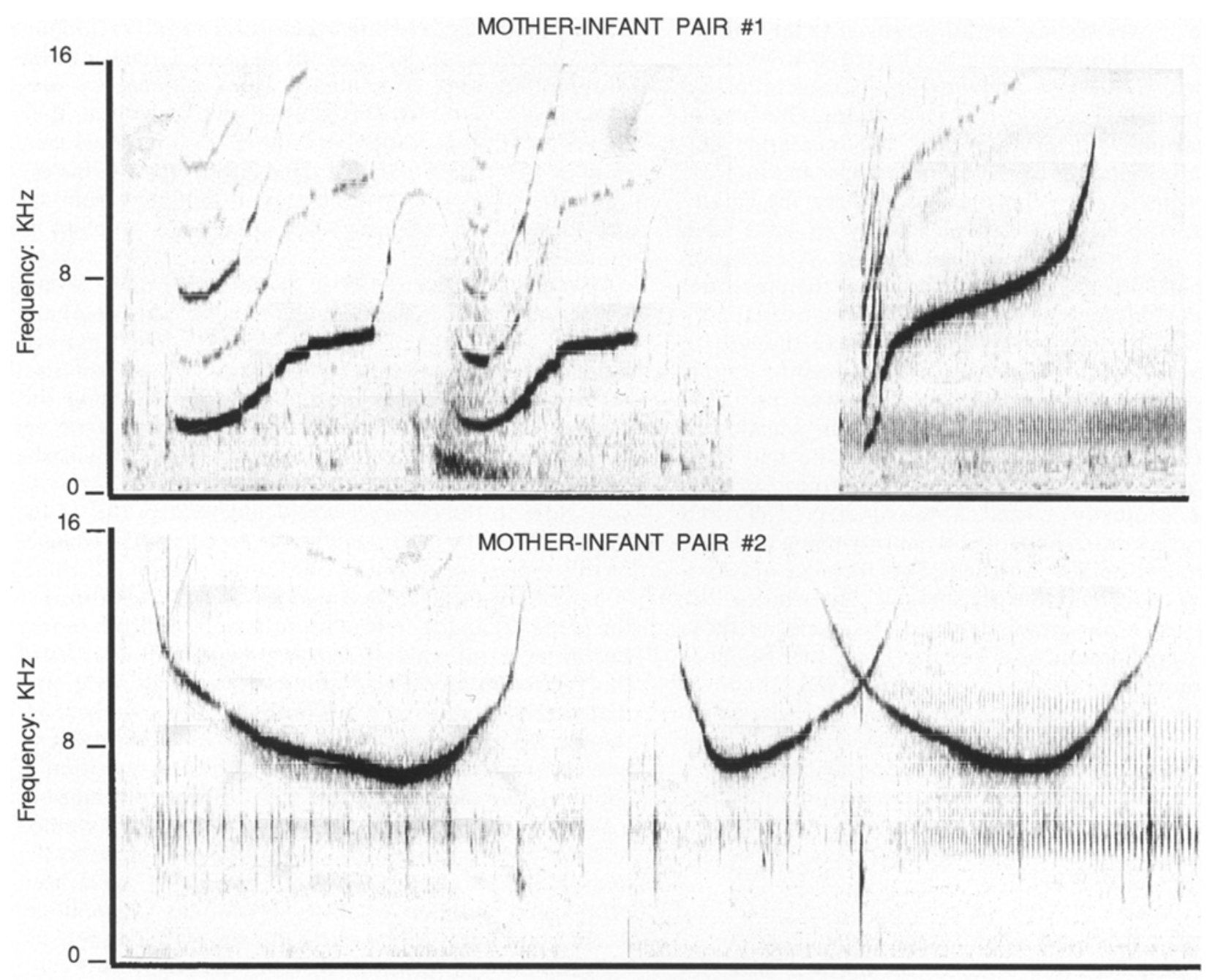

Time : sec

Fig. 6. Whistles recorded from mothers and infants during herding at the provisioning area. Top: Examples of the whistle types recorded from mother-female infant pair 1 (mother on the left, infant

( $>50 \mathrm{~m}$ from the hydrophone) during herding context recordings, but rarely heard whistles likely to have been from mothers during offshore separations even when the mother was at a similar distance $(50 \mathrm{~m})$ from our hydrophone.

\section{Whistles during reunions among adults}

Numerous anecdotal observations indicate that adults, like mothers and infants, also use signature whistles to mediate reunions. For example, during a follow of Cookie, he and his mother Crookedfin were joined by a two young females, Joy and Joysfriend. Joysfriend fell behind the others by approximately $50 \mathrm{~m}$. Several loud whistles clearly produced by Joysfriend occurred as she traveled rapidly to catch up with the rest of her party (passing very close to us in the process). Crookedfin, Cookie and Joy stopped travelling, hung motionless (and apparently silent) at the surface as if "waiting" for Joysfriend, and resumed travel once she had rejoined. During another follow, the adult males Realnotch, Hi and Bottomhook on the right). Bottom: A single rendition and then overlapping renditions of the same (or very similar) whistle types from motherfemale infant pair 2

joined a large, socializing party of subadult males, but Bottomhook departed at 12:29. At 12:38, Realnotch and Hi broke away from the socializing party and began to travel to the north. Very loud whistles (audible even in air) were emitted by either Realnotch or Hi as they passed under our boat and continued as they traveled approximately $200 \mathrm{~m}$ to the north. Here they rejoined Bottomhook, who hung motionless as we approached, resuming travel once Realnotch and $\mathrm{Hi}$ had rejoined. We were unable to determine whether Bottomhook whistled. Note that in both of these cases, the individuals who joined whistled while the other party waited.

\section{Discussion}

Whistling in the context of reunions may benefit infants in two, not mutually exclusive ways. The first involves localization. Infants may whistle to reveal their own location and to induce the mother to whistle, thereby revealing her location. The second involves inducement of other cooperative responses from the mother such as 
approaching or waiting for the infant or whistling in response, indicating not only her location but also perhaps her willingness to be rejoined.

Mothers and infants typically travel continuously while apart, and may therefore have difficulty predicting each other's location when reunion is necessary. Because whistles are relatively low-frequency, frequency-modulated and repetitively produced sounds, they may be well-suited for localization (Wiley and Richards 1982). Dolphins may be able to locate each other through passive listening to non-whistle sounds, such as echolocation clicks, but localization could be an important function of whistles. Some of our observations (that whistles occur primarily during separations, increase in likelihood with increasing separation distance when localization is likely to be more difficult, and tend to begin prior to the process of reuniting) are consistent with the expectations of a hypothesized localization function.

Yet other observations suggest that if whistles do in fact facilitate localization, this is not their only function. Infants seem to be primarily responsible for reinstating proximity during reunions, that is, they approach their mothers rather than vice versa. In spite of the fact that infants are the ones faced with the navigational task, they also seem to whistle more than their mothers do in this context. If the success of an infant's approach typically depends upon hearing the mother whistle, we would expect to have heard mothers whistle more often than we did. It is possible that mothers hear their infants approaching, and do not whistle in response unless the infant is distressed or off course.

Additional observations support the hypothesis that infant whistles function to induce maternal cooperative responses other than whistling to reveal location. The fact that infants tend to whistle during breaks in infant position when the mother is very nearby suggests that the infant may be attempting to induce her to reinstate infant position (infants seem to rest when in infant position, and breaks in infant position may disrupt resting or nursing opportunities). Anecdotal observations of reunions among adults suggest that whistling may induce a waiting response. Mothers also sometimes waited for their infants during reunions.

In short, infant whistles could convey information about identity, location and motivation to reunite as well as querying mothers for similar information. The relative importance of these different functions is likely to vary with different circumstances and cannot be teased apart without further research, particularly on maternal responses to infant whistles.

Caldwell and Caldwell (1979) report that although whistles are present at birth, these lack distinctiveness, becoming individually distinct by 4-6 months of age. Because infants are particularly vulnerable to predation and mothers may provide some protection, we would expect that selection pressures to develop an individualized whistle and to distinguish a mother's whistle from others would greatly increase at the time when infants begin to separate from their mothers to large distances.

In many species of birds and mammals, particularly species that nest or give birth in colonies, mothers and their young use individually distinctive vocalizations to mediate reunions (birds: Beecher 1981; Jones et al. 1987; McArthur 1982; pinnipeds: Trillmich 1981; Gisiner and Schusterman 1991; Petrinovich 1974; ungulates: Epsmark 1971; Chiroptera: Brown 1976; Balcombe and McCracken 1992; carnivores: East and Hofer 1991; Peters and Wozencraft 1989). The highly individual signature whistles of dolphins suggest that unambiguous signals used to communicate identity have been favored by natural selection, due to either high costs associated with misidentification, and/or large benefits of correct identification. Subtle individual differences in vocalizations may be ineffective due to distortions of sound occurring in the aqueous medium. Distortions can result from changes in the speed of sound transmission due to temperature and/or salinity gradients, reflection of sound energy off of the surface (air/water interface) and objects on the bottom, reverberation of ensonified objects, and changes in the dolphin's sound generating apparatus under varying pressure at different water depths (Tyack 1991).

A striking parallel to the dolphin signature whistle system occurs in colonially nesting bat species such as the lesser spear-nosed bat (Phyllostomus discolor), the Mexican free-tailed bat (Tadarida brasiliensis mexicana) and the pallid bat (Antrozous pallidus) where mothers must relocate infants within the context of a creche containing hundreds or even thousands of mother-infant pairs. Like dolphins, mothers and/or infants of these bat species produce frequency-modulated calls that vary strikingly across individuals and appear to function in motherpup recognition and reunion (Brown 1976; Esser and Schmidt 1989; Balcombe and McCracken 1992). Both mothers and pups produce calls, and olfactory as well as other cues are probably used in the process of reunion. Interestingly, there is evidence that lesser spear-nosed bat infants modify their calls to resemble those of their mothers by about 50 days of age (Esser and Schmidt 1989). Bats and dolphins share another unusual characteristic, namely echolocation. It is possible that the frequencymodulated calls used by dolphins and bats are particularly well-suited to take advantage of acoustic processing mechanisms that do not interfere with the concurrent processing required for echolocation.

In conclusion, the use of highly individualized signature whistles to mediate reunions may permit dolphins to locate and join specific others with whom they choose to associate, and is therefore a key component of the fission-fusion social organizations typical of bottlenose dolphins. Dolphins begin to develop these skills as infants in the context of separations and reunions from their mothers.

Acknowledgements. Thanks to Julie Gros-Louis, Andrew Richards and Caryanne Cadman for assistance with data collection. Thanks also to Richard Connor, Andrew Richards, John Pepper, John Mitani, Amy Samuels, Warren Holmes, Peter Tyack and Laela Sayigh for helpful comments on the manuscript. Bernd Wursig and Elizabeth Gawain helped to initiate the research at Monkey Mia. This project was supported by the National Geographic Society, a National Science Foundation Presidential Young Investigator Award to BBS (BNS-8857969) and private donations to the Dolphins of Shark Bay Research Foundation, and by Woodrow Wilson and American Association of University Women Fellowships to JM. Logistical support from the West Australian Museum, The 
University of West Australia Department of Human Biology, The Department of Conservation and Land Management in West Australia, the Shire of Shark Bay and the rangers at Monkey Mia is gratefully acknowledged.

\section{References}

Altmann J (1974) Observational study of behavior: sampling methods. Behaviour 49:227-265

Balcombe JP, McCracken GF (1992) Vocal recognition in Mexican free-failed bats: do pups recognize mothers? Anim Beh 43:79-87

Ballance LT (1990) Residence patterns, group organization and surfacing associations of bottlenose dolphins in Kino Bay, Gulf of California, Mexico. In: Leatherwood S, Reeves RR (eds) The bottlenose dolphin. Academic Press, San Diego, pp 267-283

Beecher MD (1981) Development of parent-offspring recognition in birds. In: Aslin RK, Alberts JR, Petersen MR (eds) Development of perception, vol 1. Academic Press, New York

Brown P (1976) Vocal communication in the pallid bat, Antrozous pallidus. Z Tierpsychol $41: 4-54$

Caldwell MC, Caldwell DK (1965) Individualized whistle contours in bottlenose dolphins (Tursiops truncatus). Nature 207:434-435

Caldwell MC, Caldwell DK (1968) Vocalizations of naive captive dolphins in small groups. Science 159:1121-1123

Caldwell MC, Caldwell DK (1971) Statistical evidence for individual signature whistles in Pacific white-sided dolphins, Lagenorhynchus obliquidens. Cetology 3:1-9

Caldwell MC, Caldwell DK, Miller JF (1973) Statistical evidence for individual signature whistles in the spotted dolphin, Stenella plagiodon. Cetology 16:1-21

Caldwell MC, Caldwell DK (1979) The whistle of the Atlantic bottlenose dolphin (Tursiops truncatus): ontogeny. In: Winn $\mathrm{HE}$, Olla BL (eds) Behavior of marine animals, vol 3: cetaceans. Plenum Press, New York, pp 369-401

Caldwell MC, Caldwell DK, Tyack PL (1990) Review of the signature-whistle hypothesis for the Atlantic bottlenose dolphin. In: Leatherwood S, Reeves RR (eds) The bottlenose dolphin. Academic Press, New York, pp 199-234

Connor RC, Smolker RS (1985) Habituated dolphins (Tursiops spp.) in Western Australia. J Mammal 66:398-400

Connor RC, Smolker R, Richards AF (1992a) Dolphin alliances and coalitions. In: Harcourt AH, DeWaal FBM (eds) Coalitions and alliances in humans and other animals. Oxford University Press, New York, pp 414-443

Connor RC, Smolker R, Richards AF (1992b) Two levels of alliance formation among male bottlenose dolphins (Tursiops sp.). Proc. Nat Acad Sci 89:987-990

Dreher JJ (1961) Linguistic considerations of porpoise sounds. J Acoustic Soc Am 33:1799-1800

Dreher JJ, Evans WE (1964) Cetacean communication. In: Tavolga WN (ed) Marine bio-acoustics. Pergamon, New York, pp 373-393

East ML, Hofer H (1991) Loud-calling in a female dominated mammalian society: I. Structure and composition of whooping bouts of spotted hyaenas Crocuta crocuta. Anim Behav $42: 637-650$

Epsmark Y (1971) Individual recognition by voice in reindeer mother-young relationships: field observations and playback experiments. Behaviour 40:295-301

Esser KH, Schmidt U (1989) Mother-infant communication in the lesser spear-nosed bat (Chiroptera, Phyllostomidae) - evidence for acoustic learning. Ethology 82:156-168

Evans WE, Prescott JH (1962) Observations of the sound production capabilities of the bottlenosed porpoise: a study of whistles and clicks. Zoologica 47:121-128

Gisiner R, Schusterman R (1991) California sea lion pups play an active role in reunions with their mothers. Anim Behav $41: 364-366$
Herman LM, Tavolga WN (1980) The communication systems of cetaceans. In: Herman LM (ed) Cetacean behavior: mechanisms and functions. Wiley, New York, pp 149-209

Jones IL, Falls JB, Gaston AJ (1987) Vocal recognition between parents and young of ancient murrelets, Synthliboramphus antiquus (Aves: Alcidae). Anim Behav 35: 1405-1415

Lilly JC, Miller AM (1961) Sounds emitted by the bottlenose dolphin. Science 133:1689-1693

McArthur PD (1982) Mechanisms and development of parentyoung recognition in the pinon jay (Gymnorhinus cyanocephalus). Anim Behav 30:62-74

McBride AF, Hebb DO (1948) Behavior of the captive bottlenose dolphin, Tursiops truncatus. J Comp Physiol Psychol $41: 111-123$

McBride AF, Kritzler H (1951) Observations on pregnancy, parturition, and post-natal behavior in the bottlenose dolphin. J Mammal 32:251-266

Peters G, Wozencraft WC (1989) Acoustic communication by fissiped carnivores. In: Gittleman JL (ed) Carnivore behaviour, ecology and evolution. Chapman and Hall, London, pp 14-56

Petrinovich L (1974) Individual recognition of pup vocalization by northem elephant seal mothers. Z Tierpsychol 34:308-312

Ross GJB, Cockcroft VG (1990) Comments on Australian bottlenose dolphins and the taxonomic status of Tursiops aduncus (Ehrenberg 1832). In: Leatherwood S, Reeves RR (eds) The bottlenose dolphin. Academic Press, New York, pp 101-128

Sayigh LS, Tyack PL, Wells RS, Scott MD (1990) Signature whistles of free-ranging bottlenose dolphins Tursiops truncatus: stability and mother-offspring comparisons. Behav Ecol Sociobiol $2: 247-260$

Saayman GS, Tayler CK (1973) Social organization of inshore dolphins (Tursiops aduncus and Sousa) in the Indian Ocean. J Mammal 54:993-996

Smolker R, Richards AF (1988) Loud sounds during feeding in Indian Ocean bottlenose dolphins. In: Nachtigall P, Moore PWB (eds) Animal sonar: processes and performance. Plenum Press, New York, pp 703-706

Smolker RS, Richards AF, Connor RC, Pepper JP (1993) Sex differences in patterns of association among Indian Ocean bottlenose dolphins. Behaviour 123:38-69

Tavolga M (1966) Behavior of the bottlenose dolphin (Tursiops truncatus ): Social interactions in a captive colony. In: Norris KS (ed) Whales, dolphins and porpoises. University of California Press, Berkeley Los Angeles, pp 718-730

Tayler CK, Saayman GS (1972) The social organization and behavior of dolphins (Tursiops aduncus) and baboons Papio ursinus): some comparisons and assessments. Ann Cape Prov Mus Nat Hist 9:11-49

Trillmich F (1981) Mutual mother-pup recognition in Galapagos fur seals and sea lions: cues used and functional significance. Behaviour 78:21-42

Tyack PL (1986) Whistle repertoires of two bottlenose dolphins, Tursiops truncatus: mimicry of signature whistles? Behav Ecol Sociobiol 18:251-257

Tyack PL (1991) If you need me, whistle. Nat Hist 8:60-61

Wells RS, Irvine AB, Scott MD (1980) The social ecology of inshore odontocetes. In: Herman LM (ed) Cetacean behavior: mechanisms and functions. Wiley, New York, pp 263-317

Wells RS, Scott MD, Irvine AB (1987) The social structure of freeranging bottlenose dolphins. In: Genoways $H$ (ed) Current mammalogy, vol 1. Plenum, New York, pp 247-305

Wiley RH, Richards DG (1982) Adaptations for acoustic communication in birds: sound transmission and signal detection. In: Kroodsma DE, Miller EH (eds) Acoustic communication in birds, vol 1. Academic Press, New York, pp

Würsig B (1978) Occurrence and group organization of Atlantic bottlenose porpoises (Tursiops truncatus) in an Argentine bay. Biol Bull 154:348-359

Würsig B, Würsig M (1977) The photographic determination of group size, composition and stability of coastal porpoises. Science 198:755-756 